\title{
Estratégias de resolução de situação problema de modelagem matemática e o pensamento proporcional: um estudo com estudantes de pedagogia
}

Situation resolution strategies mathematical modelling problem and proportional thinking: a study with pedagogy students

Morgana Scheller ${ }^{1}$

Danusa de Lara Bonotto ${ }^{2}$

\section{Resumo}

O estudo objetiva compreender e identificar as estratégias utilizadas pelos estudantes de Pedagogia para resolver uma situação problema de Modelagem Matemática que podem envolver raciocínio proporcional. Para isso, um estudo de caso foi desenvolvido com uma turma de 32 estudantes do quinto semestre de Pedagogia de uma instituição pública. Os dados advieram de uma prática de Modelagem Matemática desenvolvida em sala durante o período destinado ao estudo da tendência, e foram obtidos do material elaborado pelos 13 grupos participantes. A análise evidenciou que os acadêmicos, diante da situação problema de Modelagem Matemática, fazem uso de diferentes estratégias para resolução, nas quais foi evidenciado a utilização do fator escalar multiplicativo e do fator funcional, principalmente. Dentre as estratégias, as com erro não foram identificadas e, em todas elas, há possibilidades de que sejam exploradas nos anos iniciais. Concluiu-se que, em 11 grupos, as estratégias evidenciam utilização de pensamento proporcional avançado e pré-formal.

Palavras chave: Anos inicias; Pedagogia; Proporcionalidade.

\section{Abstract}

The study aims to understand and identify the strategies used by Pedagogy students to solve a Mathematical Modelling problem situation that may involve proportional reasoning. For this, a case study was developed with a group of 32 academics from the fifth semester of Pedagogy from a public institution. Data came from a Mathematical Modeling practice developed in the classroom, in a dedicated time to study trends and were obtained from the material prepared by the 13 participating groups. The analysis showed that academics in the face of a Mathematical Modeling problem situation make use of different strategies for solving, in which a multiplicative scalar factor and a functional factor are evidenced. Among the strategies, those with errors were not identified and, in all of them, there are possibilities for them to be applied in the initial years. It was concluded that in 11 groups the strategies show the use of advanced and pre-formal proportional thinking.

Keywords: Initial years; Pedagogy students; Proportionality.

\footnotetext{
${ }^{1}$ Instituto Federal Catarinense | morganascheller@yahoo.com.br

${ }^{2}$ Universidade Federal da Fronteira Sul | danusabonotto@hotmail.com
} 


\section{Introdução}

Neste artigo apresentam-se resultados de um estudo que buscou responder o seguinte questionamento: Que estratégias de resolução de problema são utilizadas pelos estudantes de Pedagogia em prática de Modelagem Matemática que podem envolver o raciocínio/pensamento proporcional? A indagação surge em um contexto de formação inicial que considera importante lecionar matemática nos anos iniciais a partir da resolução de problemas desafiadores, tais como aqueles relacionados à pesquisa, pois dessa forma o professor "[...] instiga o estudante no sentido da curiosidade em direção ao mundo que o cerca, gera inquietude, possibilitando que o estudante possa ser protagonista na busca de informações e de saberes, quer sejam do senso comum, escolares ou científicos" (BRASIL, 2013, p. 164).

Entre as atribuições profissionais dos estudantes de Pedagogia, encontra-se a de adquirir conhecimento didático do conteúdo (SHULMAN, 1987) para o ensino de matemática e, uma das formas de adquirir tal conhecimento é conhecendo as tendências metodológicas, dentre elas a Modelagem Matemática ${ }^{3}$, para que dela se possa fazer uso no processo de ensino e de aprendizagem.

Nessa direção, os documentos oficiais sugerem que o ensino de matemática no Ensino Fundamental deve pautar-se em atividades que garantam aos estudantes 0 desenvolvimento de competências, tais como "[...] desenvolver o raciocínio lógico, o espírito de investigação e a capacidade de produzir argumentos convincentes, recorrendo aos conhecimentos matemáticos para compreender e atuar no mundo" (BRASIL, 2018, p. 267). Assim, acredita-se que a Modelagem Matemática pode contribuir para o desenvolvimento de competências como essa e, para isso, necessita que os professores tenham conhecimento para utilizá-la em seu fazer desde o início da Educação Básica.

Nesse cenário, em um curso de formação inicial de licenciatura em Pedagogia, propiciou-se espaço para o estudo da tendência em tela. Dentre as atividades desenvolvidas, os acadêmicos vivenciaram uma prática de Modelagem Matemática que poderia ser resolvida explorando proporcionalidade, conceito pertencente à unidade temática Número e que deve ser contemplado nos currículos de matemática nos anos iniciais.

Nos anos iniciais, a proporcionalidade é uma ideia relativa ao campo multiplicativo, mas está relacionada também à Álgebra, Probabilidade e Geometria. Portanto, cabe ao Pedagogo o domínio desse conceito de modo a propor tarefas que possibilitem o desenvolvimento do raciocínio proporcional aos estudantes, dentre elas, as relacionadas com a transformação estrutural e invariância, negligenciadas nos estudos de raciocínio proporcional (LESH; POST; BEHRS, 1998). Assim, tarefas devem ser exploradas nas aulas, ao longo da escolaridade, de modo que os estudantes possam fazer uso desse tipo de

\footnotetext{
${ }^{3}$ A expressão, na Educação Matemática, é compreendida como um método de ensino com pesquisa, uma estratégia de ensina, uma alternativa pedagógica, um ambiente de aprendizagem, uma concepção de educar matematicamente, dentre outros. O foco é a utilização nos processos de ensino e de aprendizagem de modo a propiciar um processo mais significativo, dinâmico, crítico e reflexivo, que se afaste da transmissão e reprodução de conhecimentos. Bassanezi (2006), Burak (1992), Biembengut (1990; 2016), Barbosa (2001), Meyer, Caldeira e Malheiros (2011) e Almeida, Silva e Vertuan (2012) são referências no cenário nacional.
} 
raciocínio em tarefas interdisciplinares, pois são muitas das situações cotidianas que o envolve.

Os estudos pautados em proporcionalidade são vários, bem como os de Modelagem Matemática. No entanto, quando se conjugam os dois e atenta-se para a formação inicial ou atuação nos anos iniciais, o número declina. Entre os estudos encontrados, identificou-se o de Bisognin e Bisognin (2011), desenvolvido em contexto de formação continuada, onde as autoras destacam que a modelagem matemática é um caminho que pode propiciar a criação de imagens conceituais que favorecem a compreensão do conceito de proporcionalidade. Contudo, o estudo não foi realizado com futuros professores dos anos inicias, tornando pertinente verificar como isso ocorre com docentes que atuarão nessa etapa de escolaridade, que é responsável pelo início da construção do significado de proporcionalidade.

Nesse sentido, torna-se importante analisar como esses estudantes resolvem situações que podem promover o raciocínio proporcional de modo a subsidiar uma discussão posterior sobre a futura ação docente, a fim de que eles ampliem o conhecimento pedagógico do conteúdo (SHULMANN, 1987). Além disso, entender as diferentes formas de raciocínio proporcional que os estudantes aplicam em diferentes tipos de problemas é um primeiro passo para identificar maneiras de ajudar docentes e estudantes a desenvolver 0 raciocínio proporcional na sala de aula. Assim, esse estudo pretende compreender e identificar as estratégias utilizadas pelos acadêmicos de Pedagogia na resolução de uma situação problema de Modelagem Matemática que pode envolver raciocínio proporcional.

\title{
Da proporcionalidade e pensamento proporcional
}

Dentre os conceitos sugeridos desde o início da Educação Básica encontra-se o de proporção, uma vez que ela "[...] se apresenta como de utilidade geral e incontestável, não somente representando um papel fundamental na matemática, mas suas aplicações são inumeráveis e estão presentes em todos os setores da atividade humana" (DUPUIS; PLUVINAGE, 1981, p. 165). O mais recente documento normativo para o estudo curricular no Brasil, a Base Nacional Comum Curricular (BNCC), recomenda:

\begin{abstract}
A proporcionalidade, por exemplo, deve estar presente no estudo de: operações com os números naturais; representação fracionária dos números racionais; áreas; funções; probabilidade etc. Além disso, essa noção também se evidencia em muitas ações cotidianas e de outras áreas do conhecimento, como vendas e trocas mercantis, balanços químicos, representações gráficas etc (BRASIL, 2018, p. 268).
\end{abstract}

A BNCC, coadunando com Lesh, Post e Beher (1998), expressa que a proporcionalidade é uma das ideias matemáticas fundamentais, e aparece vinculada às Unidades Temáticas Número, Álgebra, Probabilidade e Geometria desde os anos iniciais. Um exemplo dado é um problema para o desenvolvimento do pensamento algébrico de crianças dos anos iniciais, a saber: "Se com duas medidas de suco concentrado eu obtenho três litros de refresco, quantas medidas desse suco concentrado eu preciso para ter doze litros de refresco? " (BRASIL, 2018, p. 270). O Quadro 1 apresenta uma síntese do documento, onde aparecem as recomendações para a exploração do conceito de proporcionalidade. 


\begin{tabular}{|c|c|c|}
\hline $\begin{array}{l}\text { Unidade } \\
\text { temática }\end{array}$ & Objeto do Conhecimento & Habilidades \\
\hline $\begin{array}{l}\text { Número } \\
4^{\circ} \text { ano }\end{array}$ & $\begin{array}{l}\text { Problemas envolvendo diferentes } \\
\text { significados da multiplicação e da } \\
\text { divisão: adição de parcelas iguais, } \\
\text { configuração retangular, } \\
\text { proporcionalidade, repartição } \\
\text { equitativa e medida }\end{array}$ & $\begin{array}{l}\text { (EF04MA 06) Resolver e elaborar problemas } \\
\text { envolvendo diferentes significados da } \\
\text { multiplicação (adição de parcelas iguais, } \\
\text { organização retangular e proporcionalidade), } \\
\text { utilizando estratégias diversas, como cálculo por } \\
\text { estimativa, cálculo mental e algoritmos. }\end{array}$ \\
\hline $\begin{array}{l}\text { Álgebra } \\
5^{\circ} \text { ano }\end{array}$ & $\begin{array}{l}\text { Grandezas diretamente } \\
\text { proporcionais } \\
\text { Problemas envolvendo a partição } \\
\text { de um todo em duas partes } \\
\text { proporcionais }\end{array}$ & $\begin{array}{l}\text { (EF05MA12) Resolver problemas que envolvam } \\
\text { variação de proporcionalidade direta entre duas } \\
\text { grandezas, para associar a quantidade de um } \\
\text { produto ao valor a pagar, alterar as quantidades } \\
\text { de ingredientes de receitas, ampliar ou reduzir } \\
\text { escala em mapas, entre outros. } \\
\text { (EF05MA13) Resolver problemas envolvendo a } \\
\text { partilha de uma quantidade em duas partes } \\
\text { desiguais, tais como dividir um a quantidade em } \\
\text { duas partes, de modo que uma seja o dobro da } \\
\text { outra, com compreensão da ideia de razão entre } \\
\text { as partes e delas com o todo. }\end{array}$ \\
\hline $\begin{array}{l}\text { Geometri } \\
\text { a } 5^{\circ} \text { ano }\end{array}$ & $\begin{array}{l}\text { Ampliação e redução de figuras } \\
\text { poligonais em malhas } \\
\text { quadriculadas: reconhecimento } \\
\text { da congruência dos ângulos e da } \\
\text { proporcionalidade dos lados } \\
\text { correspondentes }\end{array}$ & $\begin{array}{l}\text { (EF05MA18) Reconhecer a congruência dos } \\
\text { ângulos e a proporcionalidade entre os lados } \\
\text { correspondentes de figuras poligonais em } \\
\text { situações de ampliação e de redução em malhas } \\
\text { quadriculadas e usando tecnologias digitais. }\end{array}$ \\
\hline
\end{tabular}

Quadro 1 - Excertos da BNCC em que sugerem o estudo de proporcionalidade. Fonte: Elaborado pelo autor (es) a partir de Brasil (2018, p. 295-297).

Outra referência é o material elaborado pelo Ministério da Educação, pertencente ao Programa Nacional de Alfabetização na Idade Certa, o PNAIC. De acordo com Brasil (2014), já na fase de Alfabetização Matemática, a proporcionalidade deverá ser abordada quando as crianças utilizarem o raciocínio relativo ao campo conceitual multiplicativo, uma vez que ele envolve, dentre outros, buscar "[...] um valor numa variável que corresponda a um valor em outra variável. [...] ações de correspondência um para muitos [...]" (BRASIL, 2014, p. 33). Para isso, traz um esquema que relaciona o 'número de caixas de lápis de cor' e a 'quantidade de lápis', ilustrado na Figura 1.

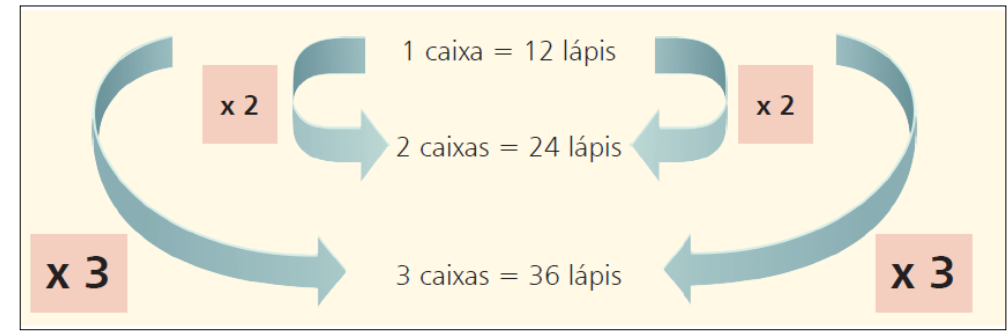

Figura 1 - Esquema que ilustra a relação entre número de caixas e o total de lápis de cor. Fonte: Brasil (2014, p. 33). 
A correspondência "um para muitos", "dois para o dobro de muitos" e assim por diante, é a base do conceito de proporção. A proporção entre as coleções permanece constante, mesmo quando o número de caixas e de lápis muda. A proporção é a expressão da relação existente entre as duas coleções (BRASIL, 2014, p. 33).

O estudo de Beher, Lesh e Post (1995) assinala que as situações de proporcionalidade, para o desenvolvimento do pensamento proporcional, devem ser introduzidas fazendo uso de noções do campo multiplicativo. Por conseguinte, o professor polivalente necessita propiciar situações diversas para que as crianças desenvolvam o pensamento proporcional, que de acordo com Lamon (2005), não é entendido como sinônimo de proporcionalidade, mas como condição essencial para a compreensão e entendimento de contextos e aplicações com base na proporcionalidade. Já para Lesh, Post e Behr (1988, p. 93), o raciocínio proporcional é

[...] uma forma de raciocínio matemático que envolve um senso de covariação e de comparações múltiplas, bem como a capacidade de armazenar e processar mentalmente várias partes de informação. [Esse tipo de pensamento] está bastante relacionado com a inferência e a predição e envolve método de pensamento tanto qualitativos quanto quantitativos.

Assim, de acordo com os autores, o raciocínio proporcional implica na correta compreensão de uma relação constante entre duas grandezas (invariância) e na noção de que essas grandezas variam em conjunto (covariação). Tal raciocínio poderá ser instigado por meio de diferentes estratégias de resolução que farão uso de diversas formas de representação, tais como palavras, desenhos, esquemas, tabelas ou símbolos matemáticos (SPNILLO, 1997; VERGNAUD, 1983). Além disso, Costa e Ponte (2008), a partir das compreensões de Lamon (2005), destacam que o raciocínio proporcional extrapola o caráter mecânico de resolução de problemas, associando-se a capacidade de analisar relações entre as quantidades de modo a explicar suas estratégias por meio de argumentos plausíveis.

De acordo com a BNCC, a proporcionalidade também contribui para a exploração da unidade temática 'Álgebra', uma vez que o pensamento proporcional é a base para esse campo da matemática (BEHR; LESH; POST, 1995). Esse tipo de pensamento, "[...] por um lado, é o culminar dos alunos da escola primária e por outro lado, é o alicerce de tudo o que segue" (LESH; POST; BEHER, 1988, p. 94), ou seja, alicerce da álgebra e de outras áreas e culminar dos conceitos de aritmética elementar, de número e de medida. Portanto, desde os anos iniciais, a criança já pode estar envolvida com situações que envolvem razão, taxa de variação, regularidade, dentre outros. Além disso, ela já pode diferenciar situações que são e que não são proporcionais.

Na perspectiva da psicologia, Piaget e Beth (1966) defendem que o raciocínio proporcional é uma capacidade que conduz à evolução conceitual significativa dos níveis operacionais do pensamento concreto para os níveis operacionais formais do pensamento. Assim, esse tipo de raciocínio desenvolve-se "(1) desde uma estratégia compensatória global (frequentemente de natureza aditiva) passando por (2) uma estratégia multiplicativa sem generalização a todos os casos, até (3) à estruturação final da lei das proporções" (LESH; POST; BEHER, 1988, p. 110). 
A respeito de estratégias de resolução de problemas que envolvem proporcionalidade antes do ensino formal do conceito ou contato com a 'regra de três', dentre outros, destacam-se os trabalhos de Viana e Miranda (2016), Costa e Ponte (2008), Oliveira (2009) e Spinillo (1994), Sousa, Palhares e Oliveras (2015), dentre outros. Os primeiros autores analisaram as estratégias empregadas por estudantes do sexto ano para a resolução de problemas de valor omisso e comparação. Os resultados indicaram que a maioria utilizou a relação de covariação para a resolução, no caso de problemas de valor omisso.

Costa e Ponte (2008), na primeira parte do estudo com estudantes de 10 a 14 anos, identificaram que, antes do ensino formal, a maioria utilizava estratégias aditivas, outros, as multiplicativas. Já Oliveira (2009), ao desenvolver um estudo com estudantes de 13-14 anos, identificou diferentes estratégias utilizadas nas resoluções: linear; escalar; funcional; de valor unitário; de grandeza intermediária. Spinillo (1994), ao estudar estratégias utilizadas por crianças de 6 a 8 anos, identificou que elas se apoiam na ideia da 'metade'. Quando as estratégias para a resolução de situações de proporcionalidade (valor omisso e comparação) são voltadas para estudantes de pedagogia, Silva, Cândido e Souza (2018) indicam que a estratégia mais utilizada é a da taxa unitária, e que são inexistentes estratégias funcionais e escalares.

Apesar dos vários estudos realizados, Silvestre (2006) afirma que não é possível identificar os motivos que levam os estudantes a escolher entre uma ou outra estratégia. Para a autora, depende de vários fatores, como o tipo de tarefa e a localização de uma melhor relação numérica, além do conhecimento matemático e habilidade de interpretação e resolução de problemas.

\section{Procedimentos metodológicos}

Na busca por compreender e identificar as estratégias utilizadas por estudantes de Pedagogia na resolução de situações-problema de Modelagem Matemática que podem envolver relação de proporcionalidade, o estudo segue uma abordagem qualitativa e interpretativa (BOGDAN; BIKLEN, 1994; ALVES-MAZZOTTI, 1998), uma vez que se preocupa com a compreensão detalhada dos significados atribuídos pelos participantes da pesquisa. Trata-se de um estudo de caso, pois consiste na "[...] observação detalhada de um contexto, ou indivíduo, de uma única fonte de documentos ou de um acontecimento específico" (BOGDAN; BIKLEN, 1994, p. 89).

O estudo foi desenvolvido no primeiro semestre de 2019, em uma Instituição Pública que oferta, também, ensino superior na modalidade de licenciatura. Participaram do estudo 32 estudantes de uma turma de quinta fase do curso de Pedagogia, matriculados no componente curricular de Fundamentos e Metodologia em Matemática, componente esse que possui 90 horas (60h + 30h de prática como componente curricular) de carga horária, 16 delas voltadas ao estudo dos fundamentos da Modelagem Matemática (MM) na Educação Matemática. Esse estudo de 16 horas permitiu que os estudantes perpassassem pelas dimensões descritas por Scheller, Bonoto e Biembengut (2015): aprender por meio da MM; aprender sobre MM e adaptar o processo para o ensino de Matemática.

Nesse intervalo de 16 horas, a tarefa inicial consistiu em vivenciar uma prática de Modelagem Matemática proposta pelo professor, que elegeu o episódio referente a temperatura de ebulição da água. Ela foi desenvolvida durante quatro horas/aula e discutida posterirormente por mais duas horas/aula. Foi nesse período que originou o 
corpus de dados para a pesquisa. No Quadro 2, apresenta-se o texto que iniciou as discussões de Modelagem.

\section{Prática de Modelagem Matemática}

Tudo começa com uma história curiosa que aconteceu comigo, a qual ilustra como surgem algumas das atividades que desenvolvo com meus estudantes. Em 2016, no primeiro semestre, meu esposo foi a um encontro de geógrafos da América Latina, em La Paz (Bolívia). Como temos o hábito de tomar chimarrão, lá vai ele com o material para onde quer que vá!

Enquanto ele estava lá conversávamos todos os dias e, logo na chegada, após a primeira refeição matinal, comentou-me que havia percebido que seu café estava 'choco' e que, no outro dia, iria mais cedo para a fim de obter a bebida em temperatura mais elevada. Logo após, ainda no mesmo dia, ocorreu o fato similar com a água que pegara na cozinha do hotel para tomar seu mate.

No dia seguinte, foi ele cedo para o café da manhã pois queria tomar café 'quente' (para não dizer pelando) e logo veio o desapontamento: o café quase morno, dizia ele. Em nossa conversa, na sequência, após novamente destacar o fato, me dei conta de algo e exclamei:

- Adilson, atente-se a localização de La Paz! A água nunca vai ficar 'quente' como você quer, em condições normais. Alouuuuu baby!

Rimos da situação, afinal jamais tínhamos parado para pensar sobre o fato ou fenômeno. A partir de tal acontecimentos, acendeu uma "lâmpada imaginária" na minha cabeça e expressei: - isso vai dar uma excelente atividade para meus estudantes! Me coloquei a levantar dados e informações para verificar se minha ideia era viável. Dentre o que li, localizei: "La Paz - altitude de 3.636 m, pressão de $0,65 \mathrm{~atm}$ e $88^{\circ} \mathrm{C}$ como temperatura de ebulição da água ". Continuei os estudos e logo elaborei uma tarefa que desafio vocês hoje a responderem:

Qual a temperatura de ebulição da água em Rio do Sul, onde estamos localizados? Afinal, Rio do Sul, provavelmente, não possui altitude e nem pressão atmosférica igual a La Paz. Estude você também e determine a temperatura de ebulição da água aqui em Rio do Sul. Responda fundamentando-se sua resposta.

Quadro 2 - Texto compartilhado com os estudantes, desencadeador da prática de Modelagem.

Os dados foram constituídos a partir de materiais produzidos pelos estudantes, ou seja, trabalhos elaborados pelos 13 grupos (T1, T2, ...T13) que configuram como 'expressão do processo e do resultado'. Na visão de Biembengut (2016, p. 78), a "[...] importância de uma representação externa não consiste em apenas expressar da forma mais plausível uma situação ou um contexto compreendido e significado, mas, especialmente, propiciar a outrem contemplar, utilizar, servir-se" dos resultados. Destaca-se que a última parte, a sistematização e expressão do processo e do resultado, foram realizadas em espaço extraescolar.

A análise dos dados foi realizada mediante observação, interpretação e avaliação minuciosa dos dados obtidos, subsidiados pelos conceitos e definições e de resultados de estudos já realizados sobre pensamento/raciocínio proporcional e estratégias de resolução de problemas, de modo a permitir o estabelecimento de categorias emergentes. 


\section{Resultados e discussão}

A situação proposta aos acadêmicos gerou apreensão inicial, visto que os mesmos possuíam poucas informações sobre o assunto, tampouco familiaridade com esse tipo de atividade. No entanto, como estavam no laboratório de informática, o professor orientou para que os mesmos buscassem inteirar-se com o assunto, destacando: "Procurem ler sobre o assunto e, a partir de informações e dados, também pensem em como crianças dos anos iniciais resolveriam essa situação. Afinal, vocês vão trabalhar com elas desenvolvendo atividade semelhante. Não esqueçam que vocês devem justificar a resposta e o procedimento adotado".

A partir da mediação, todos os grupos concentraram-se na situação problema considerada por eles. Apenas um dos grupos não começou logo por determinar a altitude da localidade Rio do Sul, ao passo que vários deles logo digitaram, no Google, "temperatura de ebulição da água em Rio do Sul", não obtendo êxito. No entanto, todos passaram a ler sobre a possível relação entre altitude, pressão atmosférica e temperatura de ebulição da água. Obtidas as informações e dados, todos os grupos passaram a pensar e discutir sobre estratégias de resolução. Registra-se que os grupos T11 e T2 encontraram maior dificuldade sobre como poderiam resolver a situação e que dados deveriam escolher para iniciar.

Na busca por responder a situação "Qual a temperatura de ebulição da água em Rio do Sul, SC, onde estamos localizados?", os resultados indicaram que os acadêmicos utilizaram distintas estratégias de resolução, com destaque às categorias de análise: (i) estratégia escalar multiplicativa; (ii) estratégia linear - combinação de estratégia multiplicativa e aditiva; (iii) estratégia de valor médio; (iv) estratégia do valor unitário ou funcional; (v) estratégia da aproximação/comparação. De modo geral, os acadêmicos procuraram estabelecer uma relação inversa, seja escalar ou funcional, entre as grandezas variáveis altitude e temperatura ou pressão atmosférica e temperatura de ebulição.

Na sequência, apresenta-se e discute-se cada estratégia utilizada pelos grupos. Todos os exemplos utilizados para a ilustração foram retirados dos trabalhos entregues antes da plenária de discussão, e serão transcritos na íntegra neste texto.

Estratégia multiplicativa ou escalar - caracteriza-se pelo uso de estratégias numéricas, como reduzir pela metade, duplicar, multiplicar por 10 e assim por diante. Denominada de estratégia multiplicativa ou estratégia escalar, tal estratégia vem assinalada pelo estabelecimento de um fator de proporcionalidade escalar entre grandezas de mesma natureza (OLIVEIRA, 2009), ou seja, dentro do mesmo espaço de medida. Essa foi a forma utilizada por um único grupo, o T6.

Na resolução, o grupo estabeleceu uma relação interna entre valores de uma mesma grandeza (metade da altitude), que implicou em metade do valor da outra (variação da temperatura), ou seja, elas precisam variar em conjunto. A isso, Behr, Lesh e Post (1995) denominam de co-variação de grandezas. Já Vergnaud (1983) denomina de relação vertical.

Com tal estratégia, os acadêmicos encontraram uma forma conveniente de simbolizar os elementos dentro de situações de proporção, bem como apoiar estratégias de pensamento para a solução ao mobilizar conhecimento sobre relação multiplicativa de covariação entre as variáveis. O excerto a seguir mostra a estratégia escalar utilizada pelo grupo T6: 
"[...] observa-se que o estado de São Paulo tem a altitude $(760 \mathrm{~m})$ em dobro ao da cidade de Rio do Sul (340m). Usando assim, a divisão/metade sobre o valor da altitude e da temperatura de ebulição $\left(97,6^{\circ} \mathrm{C}\right)$ chega-se ao resultado em que o ponto de ebulição da água na cidade de Rio do Sul será entre $98,6^{\circ} \mathrm{C}$ até $98,8^{\circ} \mathrm{C}$, pois $380 \mathrm{~m}$ é um pouco mais que $340 \mathrm{~m}$. Assim temos $100^{\circ} \mathrm{C}$ $-97,6^{\circ} \mathrm{C}=2,4^{\circ} \mathrm{C}$, como Rio do sul tem altitude pela metade, logo a temperatura será $700^{\circ} \mathrm{C}$ menos a metade de $2,4^{\circ} \mathrm{C}$, que será um pouco menos de $98,8^{\circ} \mathrm{C}$."

Acredita-se que a escolha da estratégia pela relação multiplicativa dos dados dentro da grandeza (razão) pode ter sido feita devido ao reconhecimento de uma estrutura numérica baseada em submúltiplos, visualmente mais fácil de ser identificada que uma relação horizontal.

Estratégia linear - esse tipo de estratégia resulta da combinação entre uma estratégia multiplicativa e uma estratégia aditiva. Os acadêmicos estabeleceram uma relação entre grandezas de mesma natureza, com estabelecimento de fator escalar e, para isso, utilizaram uma estratégia multiplicativa e aditiva para determinar o resultado. A Figura 2 ilustra a estratégia.

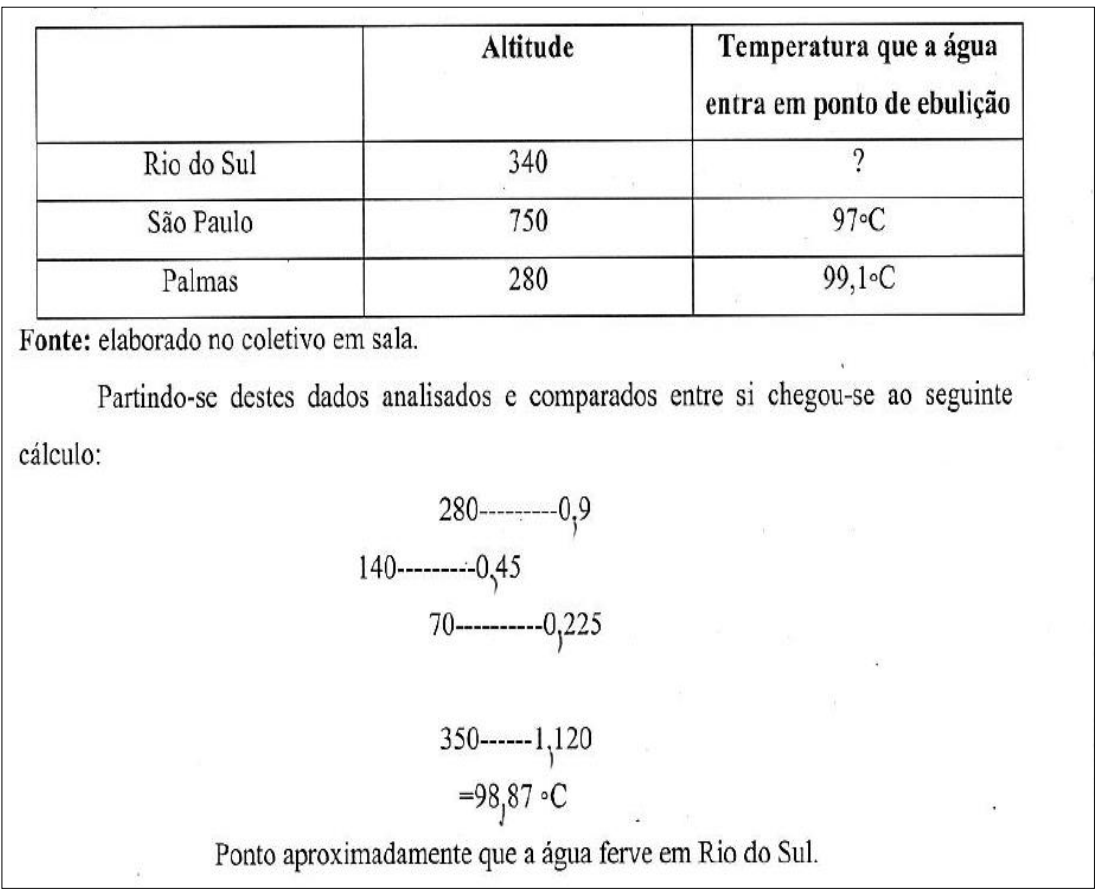

Figura 2 - Estratégia feita pelos grupos T2, T7 e T8. Fonte: T2.

A estratégia linear foi utilizada pelos grupos T2, T7 e T8 quando optaram em determinar a temperatura de ebulição da água em um local cuja altitude é de aproximadamente $340 \mathrm{~m}$. Os grupos fizeram uso de uma soma dos valores de $280 \mathrm{~m} \mathrm{e} 1 / 4 \mathrm{do}$ mesmo. Inicialmente, utilizaram a estratégia linear $(280 \mathrm{~m}+1 / 4$ de $280 \mathrm{~m}=350 \mathrm{~m})$ para encontrar os $350 \mathrm{~m}$ de altitude do local. Logo, aplicaram o mesmo fator escalar na variação da temperatura, obtendo $\left(0,9^{\circ} \mathrm{C}+1 / 4\right.$ de $\left.0,9^{\circ} \mathrm{C}\right) 1,12^{\circ} \mathrm{C}$ de temperatura a menos que no nível do mar. Dessa forma, os acadêmicos estabeleceram a relação constante (covariação de acordo com Behr, Lesh e Post (1995)) entre os valores da altitude, acrescentando 1/4 do valor original obtido $(280 \mathrm{~m})$ para obter a resposta. 
Observa-se que o resultado da temperatura de ebulição foi obtido utilizando uma combinação entre a estratégia multiplicativa e a estratégia aditiva, quando encontraram sucessivas metades dos valores de altitude e variação da temperatura de uma cidade (estratégia multiplicativa). Vergnaud $(1983,2009)$ denomina isso de análise vertical, uma vez que a relação permite passar de uma linha para outra em uma mesma grandeza, aplicando um fator escalar. Em seguida, aproximaram-se da altitude de $340 \mathrm{~m}$, fazendo a soma de $280 \mathrm{~m}$ e $70 \mathrm{~m}$ e obtendo um valor de temperatura aproximado de $98,87^{\circ} \mathrm{C}$.

Com o uso da mesma estratégia linear, notou-se que o Grupo 7 procurou aproximarse mais do valor da temperatura de ebulição, realizando múltiplas estratégias multiplicativas combinadas com a estratégia aditiva, conforme Figura 3.

Partimos então a procura de dados que fossem aproximados aos que encontramos para Xxxx. Encontramos um artigo no Banco Internacional de Objetos Educacionais, intitulado: Termodinâmica - A Física da panela de pressão. $\mathrm{O}$ artigo trazia o número mais aproximado à cidade de Xxxxx, que foi a altitude da cidade de Palmas, com 280 metros, com ponto de ebulição da água à $99,1^{\circ} \mathrm{C}$ (CARVALHO NETO, et. al., 2016). Considerando que a altitude de Xxxx é de 339,8 metros (UABRS, 2019) realizamos as seguintes etapas:

Fomos dividindo a altura e a temperatura por dois, para depois selecionar as partes para chegar o mais próximo possível ao 339,8 metros.

\begin{tabular}{|c|l|}
\hline Altitude $(\mathrm{m})$ & Temperatura $\left({ }^{\circ} \mathrm{C}\right)$ \\
\hline $\mathbf{0}$ & $\mathbf{1 0 0}$ \\
\hline $\mathbf{2 8 0}$ & $\mathbf{9 9 , 1}$ \\
\hline 280 & $-0,9$ \\
\hline 140 & $-0,45$ \\
\hline 70 & $-0,225$ \\
\hline 35 & $-0,1125$ \\
\hline 17,5 & $-0,056 .$. \\
\hline 8,75 & $-0,028 .$. \\
\hline
\end{tabular}

Em seguida somamos o valor de $280 m+35 m+17,5 m+8,75 m=341,25 m$, chegando a um resultado aproximado à altura de $\mathrm{Xxxx}$. Em seguida somamos as diferenças das temperaturas: $0,9+0,1125+0,056+0,028$ resulta cerca de $1,09^{\circ} \mathrm{C}$. Por fim, realizamos a seguinte operação: $100^{\circ} \mathrm{C}-1,09^{\circ} \mathrm{C}=98,91^{\circ} \mathrm{C}$ (temperatura de ebulição da água no nível do mar - temperatura aproximada da diferença de altitude). Ou seja, a temperatura aproximada de ebulição da água em Xxxx é de $98,91^{\circ} \mathrm{C}$.

Figura 3 - Estratégia feita pelos grupos $T 7$ e T8. Fonte: T7.

Estratégia de consecutivos valores médios - estratégia identificada em problemas (LESH; POST; BEHR, 1988), quando se estabelece uma relação interna entre os elementos de uma grandeza por meio de uma média entre dois deles, que ocorre com a pretensão de aproximar-se da solução de problema. Portanto, é estabelecida uma relação vertical, pois os dados do problema são dispostos na forma de linhas e colunas e a relação permite passar de uma linha a outra em uma mesma grandeza por meio de um fator médio. $O$ excerto e a Figura 4 ilustram a estratégia:

"[...] montei, em três diferentes 'tabelas', o valor, em metros, de altitude e a temperatura do ponto de ebulição da água correspondente a estes, baseando-me inicialmente na cidade de Palmas, que possui valor de 280 metros, um pouco menos do que Rio do Sul (339,88 metros). Somando os valores e os dividindo em dois para obter o resultado do número entre esses dois números, procedendo da mesma maneira com relação à temperatura, chegando a um 
resultado aproximado da temperatura de ebulição de $98,89^{\circ} \mathrm{C}$, correspondente a cidade de Rio do Sul".

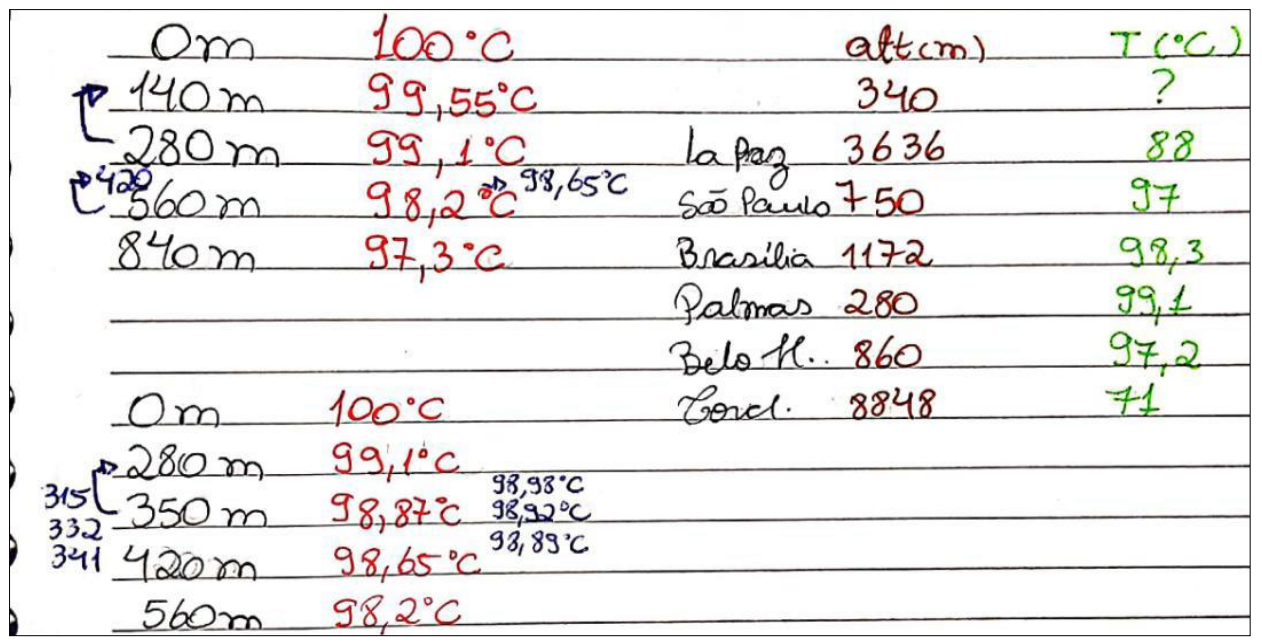

Figura 4 - Estratégia feita pelos grupos T3, T4 e T5. Fonte: T3.

A partir da visualização, percebe-se que o grupo obteve, após coleta de dados, valores de temperatura e altitude de seis lugares diferentes. Também foi registrada a altitude do lugar que desejaram encontrar a temperatura de ebulição. Dentre eles, escolheram trabalhar com os valores de altitude e temperatura de ebulição de duas localidades: (1) ao nível de mar e $100^{\circ} \mathrm{C}$; (2) $280 \mathrm{~m}$ e $99,1^{\circ} \mathrm{C}$. A seguir, partiram para estabelecer uma relação vertical, encontrando valores proporcionais das duas grandezas variáveis, por meio do valor médio.

Também fizeram uso de relação vertical e, a partir da escolha da altitude dos dois locais (280m e 0m), determinaram o valor intermediário da variação e, em seguida, por duas vezes, os múltiplos de $280 \mathrm{~m}$, obtendo $560 \mathrm{~m}$ e $840 \mathrm{~m}$. Procederam da mesma forma com os valores da variação da temperatura. Atenta-se para o fato de a altitude da localidade que desejaram encontrar a temperatura estar mais próxima com a parte inicial das informações. Diante disso, iniciaram um novo bloco de informações, registrando 0m, $280 \mathrm{~m}$ e 420m, onde determinaram o 350m (como valor médio de 280m e 420m). Reconhecendo que os valores estavam cada vez mais próximos de $340 \mathrm{~m}$, passaram a obter novos valores médios, sendo uma das referências o 350m $(350 \mathrm{~m}$ e $280 \mathrm{~m}$, depois $350 \mathrm{~m}$ e $315 \mathrm{~m}$ e, finalmente, o $350 \mathrm{~m}$ e $332 \mathrm{~m}$, obtendo o 3144m, valor muito próximo do desejado). O mesmo processo foi realizado na coluna da temperatura.

Estratégia de valor unitário ou funcional - estratégia que estabelece inicialmente o valor unitário para, em seguida, estabelecer, a partir desse valor, o resultado para o problema. Também é conhecida como relação externa entre diferentes grandezas, denominada por Vergnaud (1983) como análise horizontal ou funcional, pois há um fator de proporcionalidade estabelecendo uma relação entre duas diferentes grandezas. Já Lesh, Post e Behr (1988), Costa e Ponte (2008) e Silvestre (2006) denominam de esquema de invariância.

Essa estratégia foi utilizada por quatro grupos, mas utilizando dois modos diferentes. No primeiro caso, os grupos mobilizaram o conhecimento de invariância da relação entre as variáveis e, desta forma, fizeram uso intuitivo de noção de função ao determinar o 
coeficiente de proporcionalidade $\left(12^{\circ} \mathrm{C} / 3636 \mathrm{~m}\right)$ de $0,0033^{\circ} \mathrm{C} / \mathrm{m}$, compreendendo que isso indica que a cada metro a mais de altitude reduz a temperatura de ebulição em $0,0033^{\circ} \mathrm{C}$.

Nesse primeiro caso, tem-se a estratégia dos grupos T1 e T3 para ilustrar, que está apresentada na Figura 5.

\section{Primeiramente pesquisei a altitude de Xxxx e depois a temperatura de ebulição do nível do mar, para auxiliar na comparação e busca do resultado. Pois lembrava que a altitude do nível do mar era zero, deduzi então que seria mais fácil partir desse valor.}

Sendo assim:

$\mathrm{LaPaz}=3636 \mathrm{~m} / 88^{\circ} \mathrm{C}$

Nivel do $\mathrm{mar}=0 \mathrm{~m} / 100^{\circ} \mathrm{C}$

$\mathrm{Xxxx}=339,88 \mathrm{~m} / 2$

Para ver a diferença entre a temperatura de La Paz e o nível do mar:

$100-88=12^{\circ} \mathrm{C}$ de diferença.

Então, para descobrir quantos graus equivale para um metro de altitude, fiz uma divisão entre diferença de temperatura e altitude acima do mar de La Paz:

$12^{\circ} \mathrm{C} \div 3636 \mathrm{~m}=0,0033^{\circ} \mathrm{C} / \mathrm{m}$

Após isso, multipliquei esse valor encontrado pela altitude de $\mathrm{Xxxx}$, para saber a diferença de temperatura que há entre $\mathrm{Xxx}$ e o nível do mar:

$0,0033^{\circ} \mathrm{C} \times 339,88 \mathrm{~m}=1,21^{\circ} \mathrm{C}$ de diferença.

Por fim, diminui a temperatura do nível do mar pelo valor encontrado da diferença:

$100-1,21=98,79^{\circ} \mathrm{C}$

Portanto $98,79^{\circ} \mathrm{C}$ é a temperatura de ebulição de $\mathrm{Xxx}$.

A partir do expresso na Figura 5, percebe-se que os grupos identificaram uma regularidade na variável dependente, relação essa implícita e que auxilia na resolução do problema proposto. Destaca-se que a determinação desse coeficiente acontece posterior ao estabelecimento de comparação qualitativa, quando os acadêmicos anunciam que a 'temperatura de ebulição da água diminui com a aumento da altitude', informação obtida durante a primeira fase da Modelagem. Podem os acadêmicos ter reconhecido uma semelhança estrutural entre os componentes do problema e feito uso para obtenção da solução: "Deste modo, as questões relacionadas com a transformação estrutural e a invariância deviam ser os assuntos importantes para o raciocínio proporcional, mesmo nos níveis mais elementares" (LESH; POST; BEHR, 1988, p. 104).

Essa estratégia também é descrita por Oliveira (2009, p. 65) como "[...] busca do valor unitário", pois os acadêmicos buscam o valor que indica a unidade e, em seguida, o valor acumulado de temperatura em 339,88m, ou seja, coordenam duas operações para resolver o problema, sendo a primeira de divisão para encontrar o coeficiente de proporcionalidade e outra de multiplicação, para determinar a resposta final.

Nesse sentido, a estratégia também indica a relação de "muitos para muitos" (Se em $3636 \mathrm{~m}$ de altitude a temperatura de ebulição é $88^{\circ} \mathrm{C}$, qual será se a altitude for $339,88 \mathrm{~m}$ ?), reduzida para "uma para muitos" (a cada metro a mais de altitude reduz a temperatura de ebulição em $0,0033^{\circ} \mathrm{C}$, quanto então será a temperatura em um local com $339,99 \mathrm{~m}$ ?), 
indicada em Brasil (2014) e também presente nas situaç̃̃es problemas relativas ao campo multiplicativo, descritas por Vergnaud $(1983,2009)$.

Estratégia semelhante é utilizada em T9 e T10, conforme Figura 6.

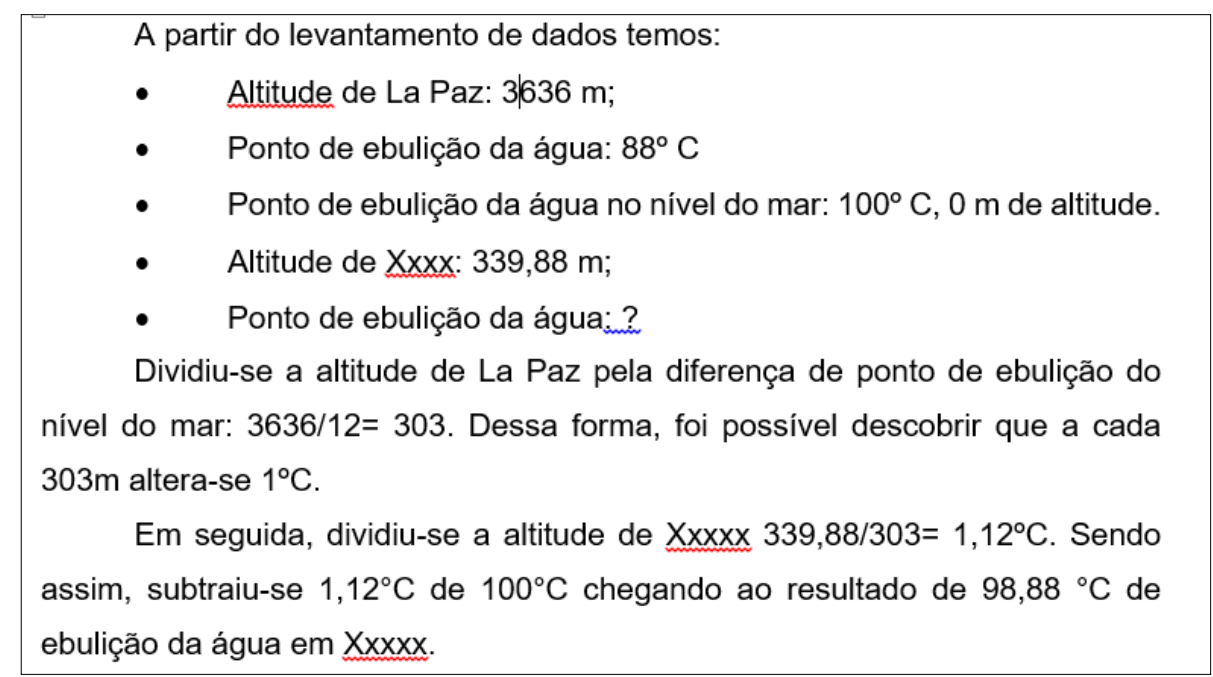

Figura 6 - Estratégia feita pelos grupos T9 e T10. Fonte: T9.

No entanto, aqui os acadêmicos optaram por estabelecer uma diferente relação fixa entre as variáveis dependente (temperatura) e independente (temperatura). Ao estabelecerem a relação entre altitude e variação da temperatura, instituem que a cada $303 \mathrm{~m}$ a temperatura de ebulição altera $\mathrm{em} 1^{\circ} \mathrm{C}$.

Estratégia da aproximação/comparação - estratégia que obtém um resultado estabelecendo comparações com valores já conhecidos considerando as duas variáveis envolvidas. Os grupos T11 e T12 utilizaram uma estratégia mais simples, estimando o valor por meio de comparação e levando em consideração a altura do local e de outros locais cuja temperatura de ebulição era conhecida. Porém, os valores expressos para a temperatura foram registrados na forma de intervalos, não ficando tão próximos se comparados aos obtidos pelos outros grupos. Suas estratégias não apresentaram nenhum cálculo ou representação pictórica para na resolução, apenas linguagem natural. Indica-se, de acordo com Parish (2010), que eles possuem pouca ou nenhuma compreensão dos problemas de proporção, pois optaram por julgamento visual, palpite ou simplesmente adivinhação.

Ao considerar o conjunto das estratégias, os grupos T2, T3, T4, T5, T6, T7 e T8 reconheceram a pertinência de estabelecer uma relação equivalente entre as grandezas de mesma natureza, começando a pensar de maneira relativa e utilizando estratégias multiplicativas para a determinação desse novo valor - a temperatura de ebulição no Rio do Sul. Assim, eles contemplaram a ideia de relação vertical (razão) dentro do mesmo espaço de medida. De acordo com Spinillo (1994), tal estratégia pressupõe compreensão. Já em T1, T9, T10 e T13, foram identificadas estratégias de resolução que contemplam ideia de taxa de variação, ou seja, uma relação horizontal (envolvendo diferente natureza), que também pressupõe compreensão, mas envolve processo cognitivo diferente do anterior. De acordo com Vergnaud (2009), este tipo de análise horizontal se situa em um nível conceitual mais 
elaborado, uma vez que não fica apenas na noção de relação numérica, mas também na de quociente $\left({ }^{\circ} \mathrm{C} / \mathrm{m}\right)$.

Assim, os resultados desses 11 grupos indicaram, no primeiro caso, a compreensão de que tais grandezas variam em conjunto (covariação) e, no segundo, a noção de relação constante em ter as duas grandezas (invariância) (LAMON, 2005; LESH; POST; BEHER, 1988), evidência da existência de pensamento proporcional. Nesse sentido, pode a Modelagem Matemática estar contribuindo com níveis mais elaborados de pensamento proporcional na perspectiva de Vergnaud (2009), pois os acadêmicos, para resolver a situação proposta, utilizaram de estratégias escalares e funcionais, estratégias essas não identificadas com os estudantes de Pedagogia do estudo descrito por Silva, Cândido e Souza (2018).

Destaca-se, também, que a maioria dos grupos fez uso de estratégias numéricas e utilização de esquemas, prevalecendo as primeiras nas estratégias de nível mais avançado de pensamento proporcional (LESH; POST; BEHR, 1998), uma vez que fizeram uso de linguagem simbólica, não juntamente com representação icônica.

Em todos os grupos, exceto em T11 e T12, foi possível identificar presença de variação numérica, característica do pensamento funcional pré-formal. Isso indica, de acordo com Parish (2010), a presença de nível avançado de pensamento proporcional, principalmente em T1, T13, T9 e T10, pensamento esse que apenas não contempla o caráter algébrico da relação, mas se configura em conhecimento base essencial para que, em anos posteriores, seja possível apropriar-se do conceito de função. Esse último pode não ter se originado, devido ao professor ter solicitado aos acadêmicos que os mesmos resolvessem a situação com conhecimentos relativos aos anos iniciais, extinguindo o algoritmo da regra de três. Destaca-se, ainda, que o nível de raciocínio proporcional mais elementar, que é o aditivo, não foi utilizado pelos acadêmicos. Os motivos não foram identificados, mas pode ser devido ao tipo de problema e os dados escolhidos para sua resolução.

\section{Considerações finais}

O estudo buscou compreender e identificar as estratégias de resolução de problemas utilizadas por acadêmicos da Pedagogia em uma prática de Modelagem Matemática, que pode envolver pensamento proporcional. A análise indicou que eles utilizam quatro tipos diferentes de estratégias: (i) escalar multiplicativa (T6); (ii) estratégia linear - combinação de estratégia multiplicativa e aditiva (T2, T7 e T8); (iii) estratégia de valor médio (T3, T4 e T5); (iv) estratégia do valor unitário ou fato funcional (T1, T9, T10 e T13); (v) estratégia da aproximação/ comparação (T11 e T12). Utilizam, prioritariamente, estratégias de resolução em que empregam o fator escalar multiplicativo e o fator funcional, evidenciado um nível elaborado de raciocínio proporcional. Acredita-se que a opção por uma determinada estratégia depende da interpretação que cada grupo fez da situação problema e dos conhecimentos que possuíam, aspectos similares identificados no estudo de Silvestre (2006).

A partir da identificação das estratégias, compreende-se que elas indicam não apenas uma compreensão de proporcionalidade, utilizando divisão e multiplicação, mas também proporcionam o desenvolvimento do raciocínio proporcional associado às habilidades de analisar situações, estabelecer relações e derivar valores, conforme descrito por Spinillo (1997). Nesse sentido, cabe discutir com esses futuros professores a pertinência, em futura ação docente, do incentivo para a resolução de problemas que priorizam mais de uma estratégia ou possíveis estratégias, o que pode proporcionar condições para o 
desenvolvimento do pensamento proporcional, pois conforme estudos descritos anteriormente, a estratégia aditiva aparece mais intensamente e é preciso evoluir para outras formas de pensamento.

Faz-se necessário, ainda, destacar com os mesmos a pertinência da discussão coletiva dessas diferentes estratégias como forma de desenvolver a argumentação dos grupos e a reflexão sobre as ideias apresentadas pelos estudantes, bem como sua validação. Nessa perspectiva, acredita-se que práticas de Modelagem Matemática que envolvam o pensamento proporcional podem incentivar os estudantes e propiciar que níveis mais elevados desse pensamento sejam mais frequentes, visto que a última etapa do processo prevê, além da validação feita no próprio grupo de trabalho, a expressão de todo o processo para os demais, que passarão a conhecer estratégias diferentes das suas e que podem contribuir para a evolução do pensamento daqueles.

O estudo revelou que o conhecimento do conteúdo em questão dos acadêmicos participantes não é o mesmo, afinal, eles expressaram estratégias de diferentes níveis cognitivos. Tal fato merece ser discutido com eles e com outros estudantes de Pedagogia, a saber, aspectos do pensamento proporcional, os diversos níveis cognitivos e as implicações desses para o processo de ensino e de aprendizagem, de modo que mesmos: (i) ampliem a compreensão do conhecimento do conteúdo; e (ii) (re)elaborem o conhecimento pedagógico desse conteúdo, uma vez que os dois são essenciais na ação docente para a garantia de qualidade do processo de ensino e de aprendizagem do tema em questão.

Em relação à limitação do estudo, acredita-se que se a professora da turma não tivesse sugerido que os grupos resolvessem considerando o modo como crianças dos anos iniciais pensam e resolvem, a estratégia do valor cruzado (regra de três) emergiria, como nos outros estudos descritos no texto. No entanto, tal estratégia não contribuiria para o desenvolvimento do conhecimento pedagógico do conteúdo desses futuros professores polivalentes, de modo a propiciar qualitativa mediação para o ensino e a aprendizagem de pensamento proporcional nos anos iniciais.

A respeito de perspectiva de continuidade, sugere-se que identificar os motivos das escolhas das estratégias pode ser um aspecto importante para redimensionar as ações dos docentes da formação inicial dos professores polivalentes.

\section{Referências}

ALMEIDA, L. M. W.; SILVA, K. P.; VERTUAN, R. E. Modelagem Matemática na Educação Básica. São Paulo: Contexto, 2012.

ALVES-MAZZOTTI, A. J. O método nas Ciências Sociais. In: ALVES-MAZZOTTI, A. J.; GEWANDSZNAJDER, F. O método nas Ciências Naturais e Sociais - pesquisa quantitativa e qualitativa. São Paulo: Editora Pioneira, 1998. p. 108-188.

BARBOSA, J. C. Modelagem Matemática: concepções e experiências de futuros professores. 2001. 268f. Tese (Doutorado em Educação Matemática) - Instituto de Geociências e Ciências Exatas, Universidade Estadual Paulista, Rio Claro, 2001.

BASSANEZI, R. C. Ensino-aprendizagem com modelagem matemática, 3. ed. São Paulo: Contexto, 2006. 
BEHR, M.; LESH, R.; POST, T. R. A proporcionalidade e o desenvolvimento de noções préalgebra. In: COXFORD, A. F.; SHULTE, A. P. (org.). As ideias da álgebra. Tradução de Hugino H. Domingues. São Paulo: Atual, 1995, p. 89-103.

BIEMBENGUT, M. S. Modelagem na Educação Matemática e na Ciência. São Paulo: Editora Livraria da Física, 2016.

BIEMBENGUT, M. S. Modelagem matemática como método de ensino aprendizagem na matemática em cursos de $1^{\circ}$ e $2^{\circ}$ graus. Dissertação (Mestrado em Educação Matemática) Universidade Estadual Paulista - Unesp, Rio Claro, 1990.

BISOGNIN, E.; BISOGNIN, V. Explorando o conceito de proporcionalidade por meio da modelagem matemática. In: Conferência Interamericana de Educação Matemática, 13, 2011, Recife. Anais [...] Recife, 2011. p. 1-10.1 CD-ROM.

BOGDAN, R. C.; BIKLEN, S. K. Investigação qualitativa em educação: uma introdução à teoria e aos métodos. Lisboa: Porto Editora, 1994.

BRASIL. Diretrizes curriculares nacionais da educação básica. Brasília: MEC, 2013.

BRASIL. Pacto Nacional pela Alfabetização na Idade Certa: Operações na resolução de problemas. Brasília: MEC, SEB, 2014.

BRASIL. Base Nacional Comum Curricular (BNCC). Educação é a Base. Brasília: MEC/CONSED/UNDIME, 2018.

BURAK, D. Modelagem Matemática: ações e interações no processo de ensinoaprendizagem. Tese (Doutorado em Educação) - Universidade Estadual de Campinas, Campinas, 1992.

COSTA, S.; PONTE, J. P. O Raciocínio Proporcional dos alunos do $2^{\circ}$ ciclo do Ensino Básico. Revista da Educação, v. 16, n. 2, p.65-100, 2008.

DUPUIS, C.; PLUVINAGE, F. La proporctionnalité et son utilisation. Recherches em Didatique des Mathématiques, La Pensée Sauvage editions, v. 2, n. 2, p. 165-212, 1981.

LAMON, S. J. Teaching Fractions and Ratios for understanding: essential content knowledge and instructional strategies for teachers. New Jersey e London: Lawrence Erlbaum Associates, Publishers, 2005.

LESH, R.; POST, T. R.; BEHR, M. Proportional Reasoning. In: HIEBERT, J.; BEHER, M. Number concepts and operations ind middle grades. Reston, VA: Lawrence Erlbaum/ NCTM, 1988. p. 93-118.

MEYER, J. F. C. A.; CALDEIRA, A. D.; MALHEIROS, A. P. Modelagem em Educação Matemática. Belo Horizonte: Autêntica, 2011.

OLIVEIRA, I. Proporcionalidade: estratégias utilizadas na Resolução de Problemas por alunos do Ensino Fundamental no Quebec. Bolema, Ano 22, n. 34, p. 57-80, 2009.

PARISH, L. Facilitating the development of proportional reasoning through teaching ratio. In: SPARROW, L.; KISSANE, B.; HURST, C. Shaping the future of mathematics education. Proceedings of the 33rd annual conference of the Mathematics Education Research Group of Australasia. Fremantle: MERGA, 2010. p. 469-476. 
PIAGET, J.; BETH, E. Mathematical epistemology and psychology. Dordrecht, Holland: Springer, 1966.

SCHELLER, M.; BONOTTO, D. L.; BIEMBENGUT, M. S. Formação Continuada e Modelagem Matemática: Percepções de Professores. Educação Matemática em Revista, v. 20, n. 46, p. 16-24. 2015.

SHULMAN, L. S. Knowledge and teaching: foundations of the new reform. Harvard Educational Review, v. 57, n. 1, p. 1-22, 1987.

SILVA, A. F. G.; CANDIDO, A. S.; SOUZA, V. H. G. Raciocínio Proporcional: um estudo sobre as estratégias de estudantes de pedagogia ao resolverem diferentes situações. Acta Scientiae, Canoas, v. 20, n. 1, p. 20-35, 2018.

SILVESTRE, A. I. Investigações e novas tecnologias no ensino da proporcionalidade directa: Uma experiência no 2. ${ }^{\circ}$ ciclo. Dissertação (Mestrado em Educação), Universidade de Lisboa, 2006.

SOUSA, F.; PALHARES, P.; OLIVERAS, M. L. Raciocínio proporcional e resolução de problemas em contextos piscatórios portugueses. Revista Latinoamericana de Etnomatemática, v. 8, n. 2, p. 76-104, 2015.

SPINILLO, A. G. Proporções nas séries iniciais do primeiro grau. In: SCHILIEMANN, A. et al. (orgs.). Estudos em Psicologia da Educação Matemática. Recife: Editora da Universidade Federal de Pernambuco, 1997. p. 40-61.

SPINILLO, A. G. Raciocínio proporcional em crianças; considerações acerca de alternativas educacionais. Pro-posições, v. 5, n. 1(13), p. 109-114, 1994.

VERGNAUD, G. Multiplicate structures. In: RESH, R.; LANDAU, M. (orgs.). Acquisitions of mathematics concepts and processes. New York. Academic Press, 1983.

VERGNAUD, G. A criança, a matemática e a realidade: problemas do ensino da matemática na escola elementar. Curitiba: Ed. da UFPR, 2009.

VIANA, O. A.; MIRANDA, J. A. O raciocínio proporcional e as estratégias de resolução de problemas de valor omisso e de comparação. Revista Eletrônica de Educação Matemática, Florianópolis, v. 11, n. 1, p. 194-213, 2016. 